\title{
A DIGITAL GAME-BASED QUADRATIC FACTORISATION LEARNING SYSTEM USING TIC-TAC-TOE
}

\author{
O. C. Agbonifo ${ }^{1, *}$ and S. Ofueu ${ }^{2}$ \\ 1, 2 Department of Computer Science, Federal University of Technology, AKure, Ondo State, NiGERIA \\ E-mail addresses:1'ocagbonifo@futa.edu.ng, 2sylvicruza@gmail.com
}

\begin{abstract}
Learning is in form of continuous process that should translate to produce knowledge. The process of learning is very crucial in the fields of education and psychology which must be planned with appropriate strategy and approach. Several researchers have made many contributions to what could increase learners' engagement in learning process that would lead to successfully learning outcome. Game technology in conjunction with learning have been attested as one of the ways that increase learners' learning motivation and attention and have hands-on experience for effective learning performance. The conventional mode of learning mathematics as a subject seems abstract, tedious and dreadful to most students but with the deployment of game technology to learning would promote entertainmenteducation for constructive and cognitive knowledge processes. Hence, a digital game-based quadratic factorisation learning system is developed using the game theory of tic-tac-toe. The system is built on Microsoft.Net Framework and game logic. The system was subjected to a performance evaluation based on six criteria such as ease of use, intuitive user interface, correctness of results, usefulness of the system to problem solving, system speed of solving the problems and memory usage by the system. The results of the analysis demonstrated that the system is efficiently suitable for the underlined objectives.
\end{abstract}

Keywords: digital game, quadratic factorisation, learning system, tic-tac-toe

\section{INTRODUCTION}

The use of gaming technology in the field of education has brought a face lift to teaching and learning and promotes students or learners to actively engage in constructive and cognitive learning practices. Students' experiences have been drastically transformed to a more highly interactive mode that connotes hands-on learning. Learning is not just rote memorization but it means acquiring the skills and thought processes needed to respond appropriately under pressure, in a variety of situations.

Learning is inherent in people and is a continuous process. The approach to learning is very significant and cannot be under emphasized. From the literature, there are various studies by researchers that revealed several approaches to teaching and learning, all with the motive to increase students' interest and participation in learning process and to enhance students' learning outcome.

Digital gaming is seen as one of the teaching and learning methods to increase students' attention and satisfaction in learning process. Game is more than mere software [3], but it is often the combination of music, art and creative imaginations [2]. Games, play and learning have enjoyed a symbolic relationship throughout recorded history. As it turns out, for many years, video game designers have been producing and refining highly motivating learning environments for their players to enjoy and as a new way to engage students.

Within an effective game-based learning environment, students are stimulated toward a goal, choosing actions and experiencing the consequences of those actions along the way. There are mistakes being made in a riskfree setting, and through experimentation, students actively learn and practice the right way to do things. This keeps students highly engaged in practicing behaviours and thought processes that can easily transfer from the simulated environment to real life [10]. Research supports the effectiveness of gamebased learning in virtual environments such as simulators with consistent aircraft training which produced training improvements compared to aircraftonly training [9].

Game-based learning is an effective way to learn mathematics. Algebra is a mathematical concept that 
seems to pose difficulty to students. There is the need of addressing the difficulty of learning algebraic equations for students to get acquainted with basic knowledge about the concept; this paper focuses on using a digital game-based learning environment to help the learners in handling factorisation. It makes use of a game mediated environment to make learning attractive that will lead to successive learning outcome.

\section{THEORETICAL FOUNDATION OF LEARNING}

The four fundamental orientations for learning theories of digital game based learning (DGBL) are described in Merriam and Cafella [8]. From the behaviourist perspective, three assumptions are held to be true. Firstly, the focus was on observable behaviour rather than on internal cognitive processes. When learning occurred, then observable external behaviour would be apparent. Secondly, the environment is the shaper of learning and behavior, not individual characteristics. Thirdly, principles of contiguity and reinforcement are central to explaining the learning process. Behavioral learning theory focuses on the drill and feedback mechanism, response system, listening, practice and content delivery.

Cognitive theory of learning are concerned with processes which occur inside the brain and nervous system when a person learns. It shares the perspective that people actively process information and learning takes place through the efforts of the learner. Internal mental processes include inputting, organising, storing, retrieving, and finding relationships between information. New information is linked to old knowledge, schema and scripts. Humanistic theory shifts the emphasis to the potential for individual growth in the learner. It brings the affective functioning of the human into the arena of learning. It starts from the assumption that every person has their own unique way of perceiving and understanding the world and that the things they do only make sense in this light.

This approach to teaching and learning has been seen to have focused on the development of a child's concept and intrinsic motivation towards learning and selfawareness. Constructivism is a learning theory in which learners construct or build self- knowledge based on experiences [7]. Interaction and experience create understanding for people, even those with varying abilities and interests [1]. Connolly et al [5] addressed two types of constructivism which are cognitive and social.

\section{RELATED WORK}

Gee [6] developed video games which relied heavily on the concept of situated learning from a sociolinguistic or semiotic perspective. The work emphasized that situations drive meaning and that meaning cannot be derived without context. The work was able to strengthen the understanding that humans make meaning from words, images, artifacts, and symbols which have meanings in a particular situation or context. It was affirmed from the digital video games situated problems in meaningful contexts where learning and performance are authentic, which decreases the disparity between how learners learn mathematics and how mathematics is being applied to real world problems.

Purtadi [12] developed a Chempuzzle game for helping students understand and memorize some chemistry concepts. The aim was to identify the effectiveness of a game on increasing student's understanding of atomic structure, elements periodic system, chemical bonding, and basic laws of chemistry. It was gathered that the chemistry curriculum required note memorization and it is quite repetitive in nature making students in this learning environment to see the mastery of the curriculum as an exorbitant task even though the concepts of the curriculum are interesting. Hence, the design of a DGBL Chempuzzle system made the curriculum stimulating and interactive.

Agbonifo and Ogunmoroti [4] developed a digital Legobased learning environment to assist the pupils in comparing fractions with like and unlike denominators to reduce the difficulty encountered by pupils when working with fractions. The platform is on a game environment that makes learning attractive for a successive learning outcome.

\section{SYSTEM DESIGN}

This section presents the architecture, flowchart, and the design process of the system.

\subsection{Game Description}

\subsubsection{Story Development}

The storyline of this game is based on a player who embarked on a journey to a known destination on a boat and suddenly, the boat capsized. Consequently, he was lost and found himself on a strange Island surrounded inhabited by a certain tribe. He was captured and taken to the Tribe's Chief. In order to regain his freedom he has to play tic-tac-toe in which a quadratic equation would be generated for him to factorise. The game must be played according to the rule and it provides necessary hints on how to leave the Island safely.

\subsubsection{Game Play}

The player is given a specific time by applying a variety of steps to get the defined problems solved. Likewise, 
the player must follow certain instructions in the course of solving the problem. The game logic provides the player with the problem solving sequences of a quadratic equation, using the tic-tac-toe graphic organizer. The player carefully follows the instruction on how to successfully mix the cell at each point in time. When the player successfully places each value from the generated equation in specific cells, then the player has successfully played the game of tic-tac-toe in learning the concept of quadratic factoring.

\subsubsection{Scoring System}

The scoring system addresses such questions as who gets what and how. As described in Sun [11], a scoring system is found in almost every of the games developed and acts as a key component in games. The idea of scoring is relatively simple. Whenever the player accomplishes a task within the game, the player is rewarded with points to add to his/her score. However, points are not limited to numeric scores; they could also be experience points, money or other valuables. As the player accomplishes tougher tasks, $s \backslash$ he gains more points. The unit of scoring in this game is experience points.

\subsection{System Architecture}

The system architecture as depicted in Figure 1 defines the underlying principles with which the system was made and explains the interconnectivity between the system modules and the associative framework.

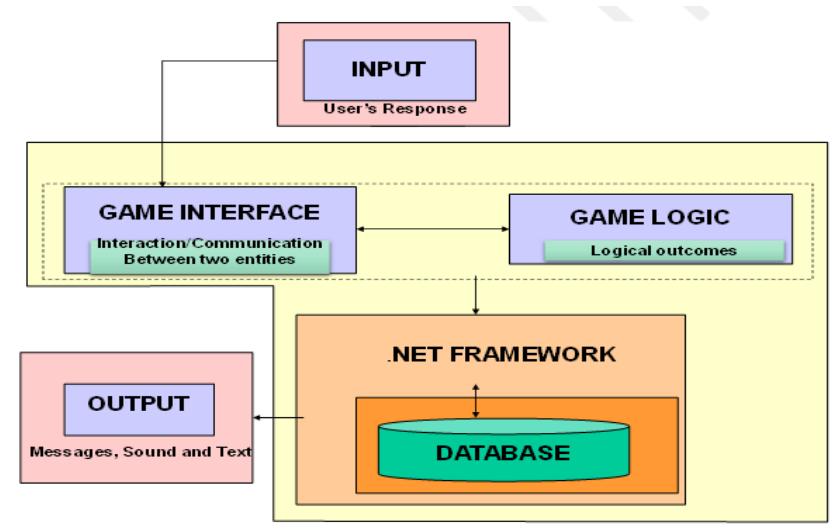

Figure 1: System Architecture

Game Interface: This is a boundary across which two independent entities meet and interact or communicate with each other. It provides the user with the visual representation and makes interaction and communication with the entities of the system possible. This is presented in this project as a tic-tac-toe grid with numbers to be placed at specific spots.

Input: This simply defines what the system reaction is all about with respect to the user's response. It is mouse and keyboard enabled allowing users to navigate through the game process. Inputs to the game are user names, the user steps into each stage as required by responding through clicking.

Game Logic: The propositional logic is employed in the development of the game, this component defines the logical outcome of the game and all the working processes. The game uses a combination of cells to successfully arrange pieces on the tic-tac-toe grid with respect to the game outcome, which is solving the quadratic equation.

Microsoft.Net Framework: The Microsoft.Net Framework provides powerful technologies such as, Extensible Application Markup Language (XAML), Windows Presentation Foundation design code view and Windows Forms to simplify developing applications and components that work seamlessly on the windows machine.

Database: The system keeps track of the player's activities such as the player' engagement and experience with the scores in the learning process, which are stored in the database.

Output: This is the outcome of the game based on the inputs provided by the player via keyboard, mouse clicking events and the logic with which player responds.

\subsection{System Flowchart}

The flowchart of the quadratic factorization system is depicted in Figure 2. It shows a procedural representation of events happening within the game. When the game is launched, it provides the player with menu options to play, exit, or check scorer board for high scorer. If the option selected is exit, the game ends. If the option selected is high score, it checks the database. If the option is play, it registers the player and verifies if the user is registered hence, he can choose the difficulty level based on how well a player can flow with the game. At the game environment, the player can either choose to quit or continue with the game. When a player continues to play the game as the game progresses, a quadratic equation is randomly generated for the player to solve by factorisation using the principle of "tic-tac-toe" game. Subsequently, the system waits for the player in a stepwise process to input the necessary values in accordance to the rules of the game and the act of factorisation before the timer runs out at 90 seconds. If the game timer is equal to zero (timer $=0$ ) then the game ends, else if timer is greater than zero (timer $>0$ ) it then checks if the input is correct. 


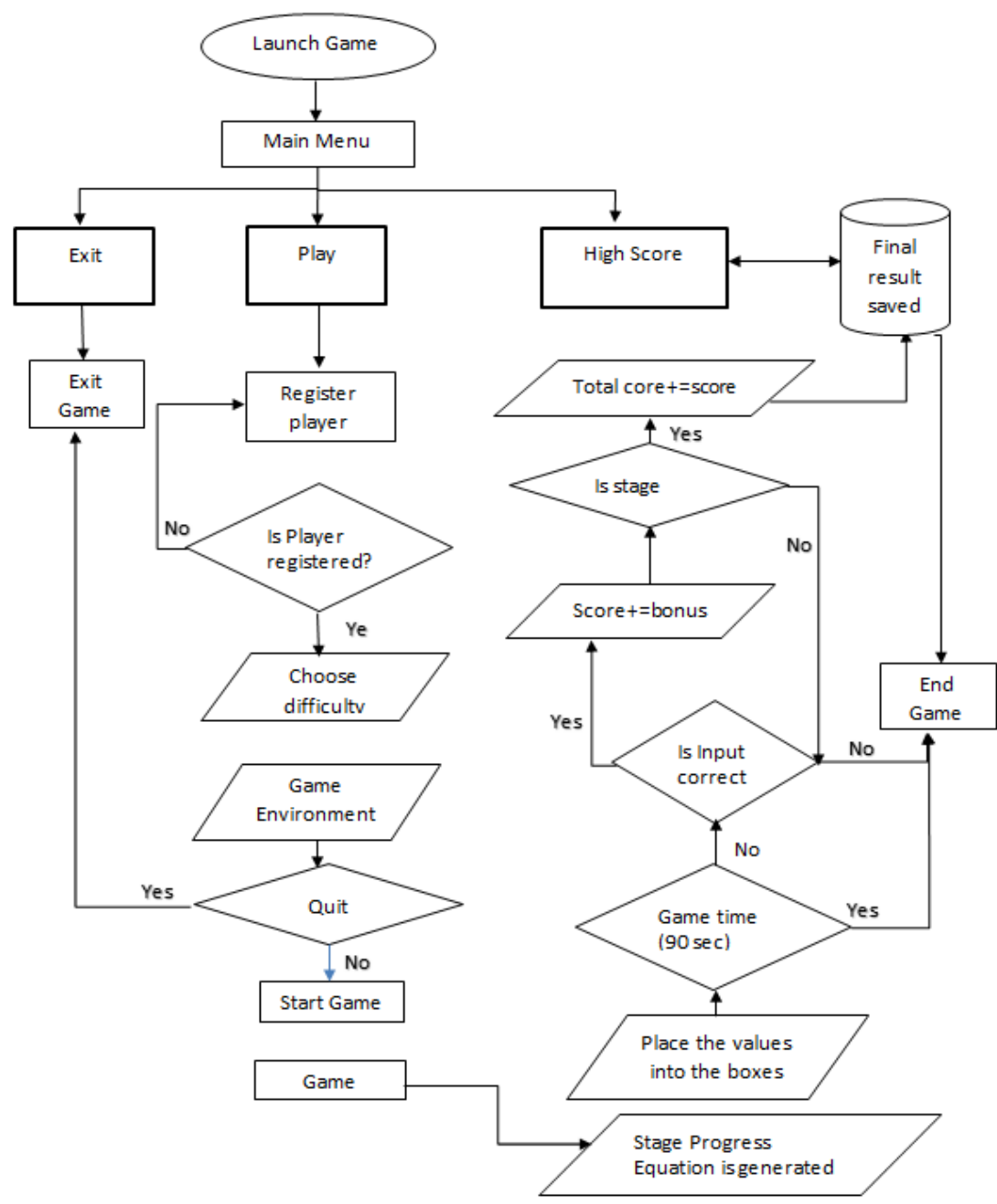

Figure 2: System Flowchart

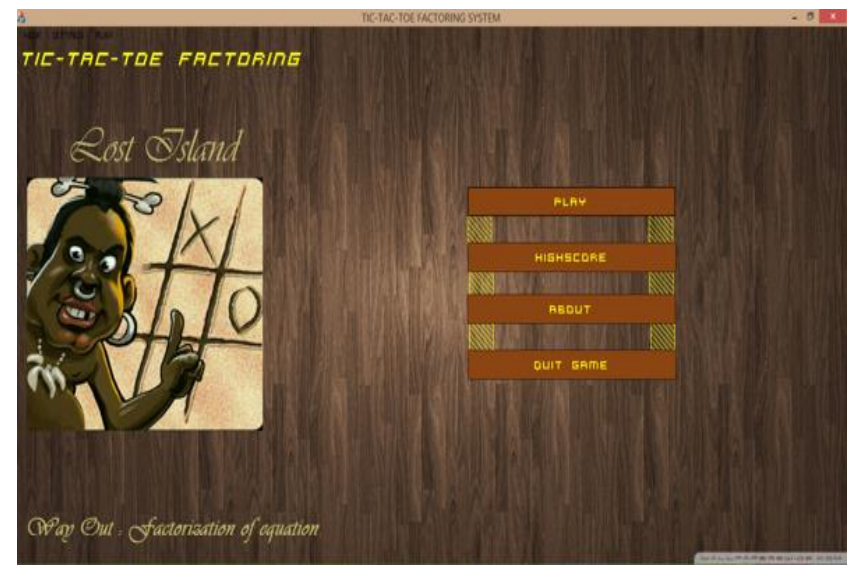

Figure 3: Interface of the game when launched

If the input is correct, the game process moves to the next stage by adding bonus to the corresponding score, else the game ends. If the stage reaches the last and task is completed, the total score is saved into the database.

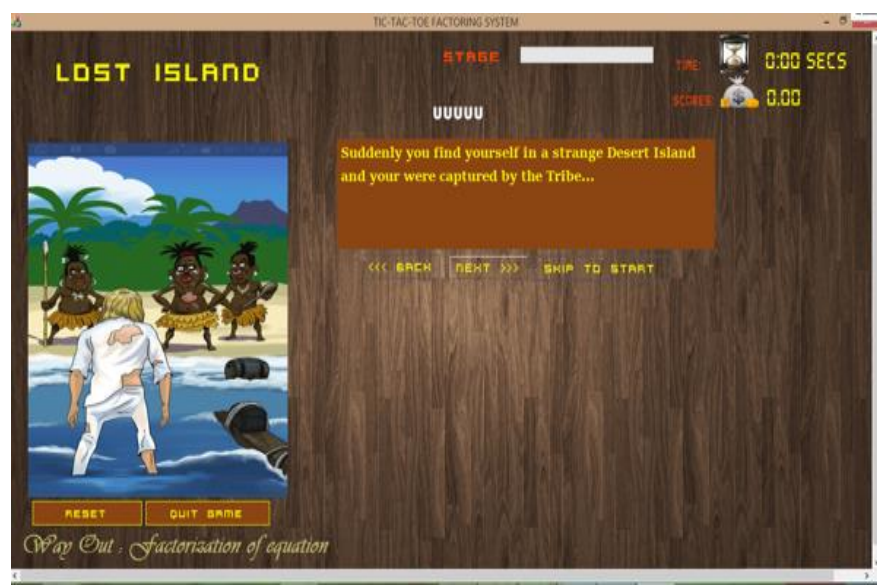

Figure 4: Storyline of the Game

\subsection{System Modules}

System modules are the set of components that are interconnected for effective performance. Figure 3 shows the interface of the when the game is launched with other menu options that the player could make a selection. Figure 4 reflects a graphical 2D animation 
and design section that entails the storyline of the game which offers the player a visual sense of the game play. In Figure 5, the quadratic equation is generated $\left(r^{\wedge} 2\right)$ $+10 \mathrm{r}+16=0$ where the player seeks to solve the equation in a stepwise process with the rule of the game (3 ' $\mathrm{X}$ ' or ' $\mathrm{O}$ ', in a straight line in either of these axes: vertical line, horizontal, and diagonal line, which shows that there are 9 cells provided in a 3 by 3 grid).

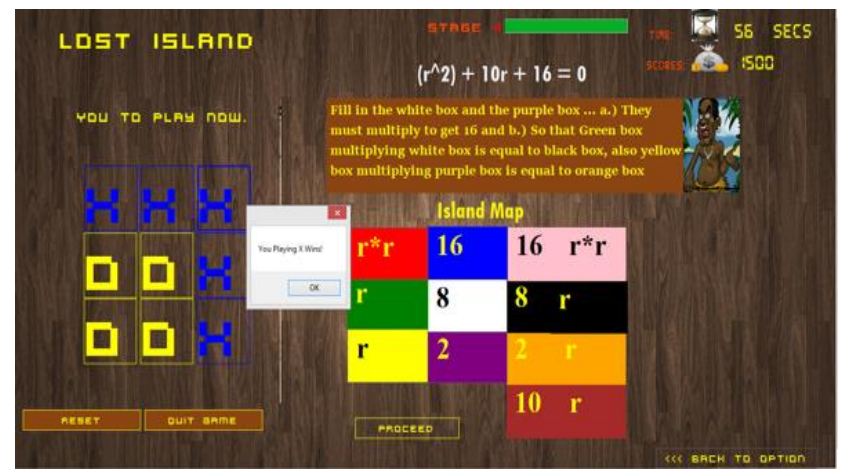

Figure 5: The Factors of the Equation are 8 and 2

When a player has successfully arranged the X's or O's in a straight line in either of the axes (vertical line, horizontal, and diagonal line), then the player gets the corresponding instruction on how the equation is to be factorized by placing values on the island map. The island map as shown in the game is a combination of colours (Red, Blue, Grey, Green, White, Black, Yellow, Purple, Orange, and Brown). When a player enters the value on the map correctly, the player eventually factorizes his way out of the Island. The player solves the quadratic equation $\left(r^{\wedge} 2\right)+10 r+16=0$ using the hints provided by the system as described thus: place $r^{*} \mathrm{r}$ on the red cell, 16 in blue cell and 10r in the brown cell, then multiply the value in the red cell and the value in the blue cell and place the result on the grey cell. This requires critical thinking by the player to find two numbers such that if added together will be $10 \mathrm{r}$ and also if multiplied together will be $16^{*}\left(r^{*} r\right)$. If the player is able to get the two numbers resolved correctly, the two numbers would be $8 \mathrm{r}$ (black cell) and $2 \mathrm{r}$ (orange cell) that add up to get $10 \mathrm{r}$ and multiply to get $16 . r^{*}$.

The player separates constant from the variable and place them in the white and purple cells respectively. The constants 8 and 2 are separated from $8 \mathrm{r}$ and $2 \mathrm{r}$ and placed on the white and purple cells while the variables $r$ are separated from $8 r$ and $2 r$ and placed on the green and yellow cells respectively.

The players' input must be the validated and if the player input is correct, the factors of the equation $\left(r^{\wedge} 2\right)$ $+10 t+16=0$ would be 8 and 2 and displayed as $(\mathrm{r}+8)(\mathrm{r}+2)$ as shown in Figure 5. Thereafter, the player can decide to quit the game to leave the island since the player has successfully placed all the values at different points on the map or to intiate another game.

\subsection{Game Simplification}

The simplification of the game for clarity is depicted in Table 1 as the island map and how the algebraic factorisation is carried out computationally with specific mathematical notations. That is, $\mathrm{X}$ for multiplication, + for addition and $=$ or || for the equality sign with relation to the colour on the island map as depicted in Figure 6.

Table 1: Game Simplification with Mathematical Notations

\begin{tabular}{|c|c|c|c|c|}
\hline $\begin{array}{c}\text { RED } \\
\left(r^{*} r\right)\end{array}$ & $X$ & $\begin{array}{l}\text { BLUE } \\
(16)\end{array}$ & $==$ & $\begin{array}{c}\text { PINK } \\
\left(16 r^{*} r\right)\end{array}$ \\
\hline 11 & & 11 & & 11 \\
\hline $\begin{array}{c}\text { GREEN } \\
(\mathrm{r})\end{array}$ & $\mathrm{X}$ & $\begin{array}{c}\text { WHITE } \\
\text { ( } 8 \text { ) }\end{array}$ & $==$ & $\begin{array}{c}\text { BLACK } \\
(8 \mathrm{r})\end{array}$ \\
\hline $\mathrm{X}$ & & $\mathrm{X}$ & & $(X /+)$ \\
\hline $\begin{array}{c}\text { YELLOW } \\
(\mathrm{r})\end{array}$ & $\mathrm{X}$ & $\begin{array}{l}\text { PURPLE } \\
\text { (2) }\end{array}$ & $==$ & $\begin{array}{c}\text { ORANGE } \\
(2 r)\end{array}$ \\
\hline & & & & $\begin{array}{c}\text { BROWN } \\
(10 r)\end{array}$ \\
\hline
\end{tabular}

Furthermore, the description of the game is given below as a form of procedure.

$($ Value in red cell $) X($ Value in blue cell $)=($ Value in pink cell)

Here the values are $\left(r^{*} r\right) X(16)=\left(16 r^{*} r\right)$

Similarly,

$($ Value in green cell $) X($ Value in white cell $)=($ Value in black cell)

Here the values are $(r) X(8)=(8 r)$

$($ Value in yellow cell $) X($ Value in purple cell $)=($ Value in pink cell)

Here the values are $(r) X(2)=(2 r)$

Also,

(Value in yellow cell) $\mathrm{X}$ (Value in green cell) $=$ (Valuesin red cell)

Here the values are $(r) X(r)=(r * r)$

Similarly,

(Value in purple cell) $\mathrm{X}($ Value in white cell $)=($ Value in blue cell)

Here the values are (2) X (8) = (16)

Also, for the two factor numbers (factor pairs)

$($ Value in black cell $)+($ Value in orange cell $)=($ Value in brown cell)

Here the values are $(2 r)+(8 r)=(10 r)$ 
(Value in black cell) $\mathrm{X}$ (Value in orange cell $)=($ Value in pink cell)

Here the values are $(2 r) X(8 r)=(16 r)$

\subsection{Game Output}

The sample output of a set of ten (10) players out of twenty that actively engaged in the game is displayed in Figure 6 and the players' scores demonstrate the degree of the understanding of game learning concept. Furthermore, the work sheet of one of the players is shown in Figure 7 to display the step-by-step process of factorising quadratic equation.

\section{RESULTS AND DISCUSSION}

Performance evaluation of the system was carried out by developing a user assessment form (questionnaire) which focusses on the following criteria such as ease of use, intuitive user interface, correctness of results, usefulness of the system to problem solving, speed of solving the problems and memory usage. The user assessment form was distributed to a set of twenty players and their responses were analysed using statistical tool (SPSS 17.0 version). The questionnaire uses 5-point likert scale such as Excellent (5), Very good (4), Good (3), Poor (2) and Very Poor (1). There were thirty questions distributed across the criteria in this order: ease of use (4), intuitive user interface (7), correctness of results (4), usefulness of the system to problem solving (5), System speed of solving the problems (5) and memory usage by the system(5). The responses of the users were analysed to determine the performance of the system based on the criteria. The results of the analysis are presented in Table 2 which showed that the system performed efficiently considering the mean and standard deviation values to minimum and the maximum values in each of the criteria.

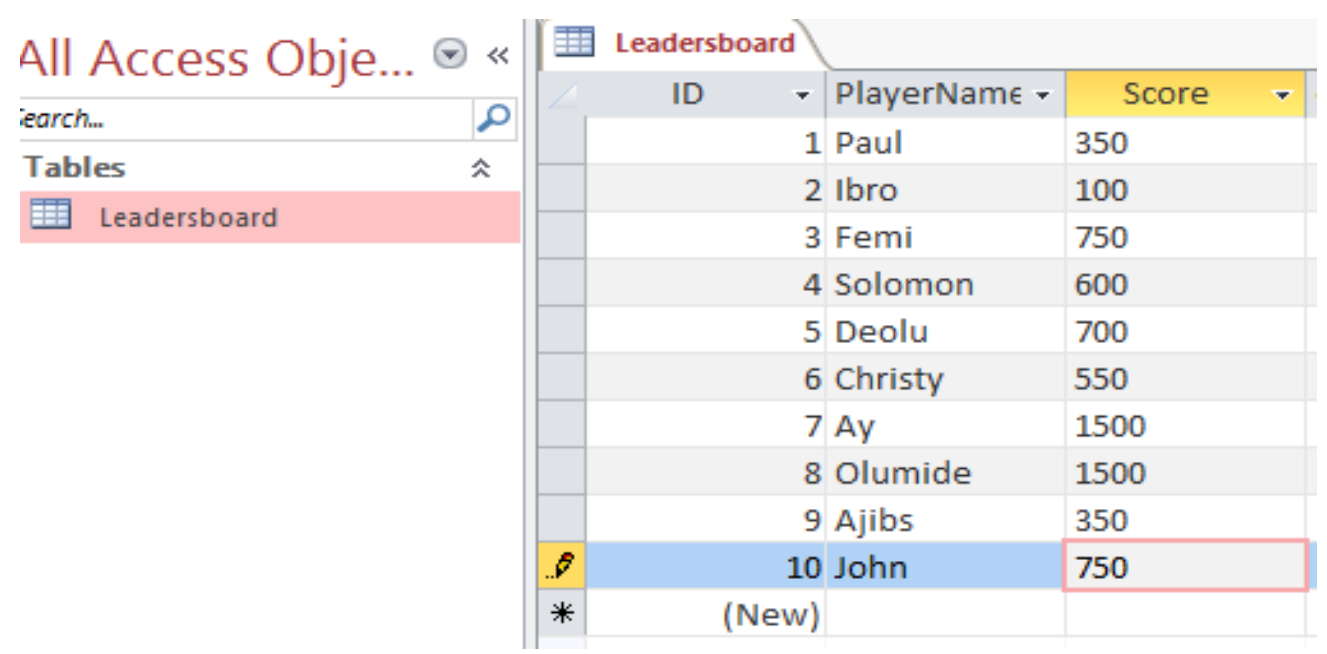

Figure 6: Sample Game Scores of Ten Players

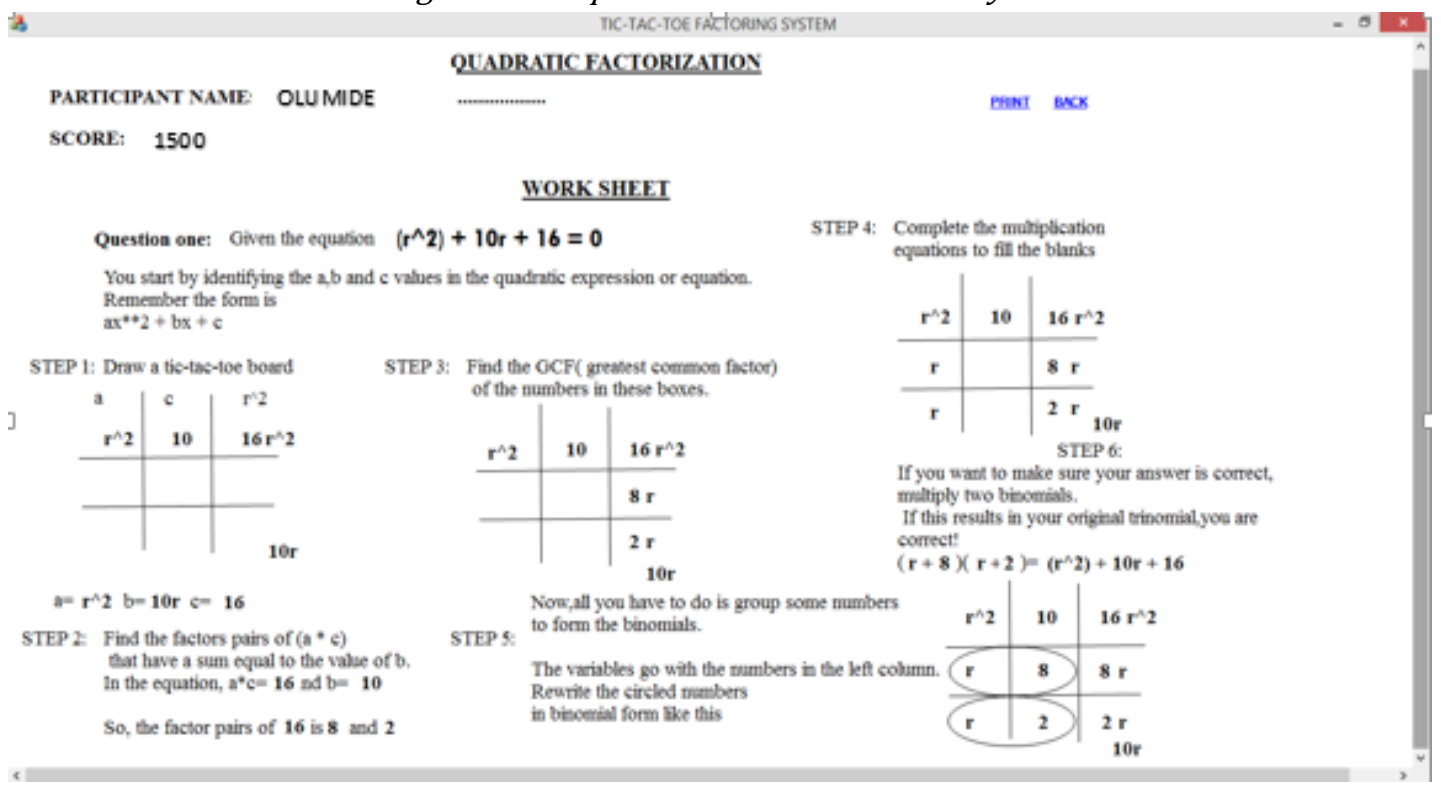

Figure 7: Sample work sheet of a Player 
Table 2: Results of Data Analysis of Evaluating the System Performance

\begin{tabular}{|c|c|c|c|c|c|c|}
\hline & $\mathrm{N}$ & Minimum & Maximum & Sum & Mean & Std. Deviation \\
\hline Ease of Use of the System & 20 & 16.00 & 20.00 & 370.00 & 18.5000 & 1.23544 \\
\hline Intuitive User Interface & 20 & 23.00 & 30.00 & 547.00 & 27.3500 & 2.30046 \\
\hline Correctness of Result of the System & 20 & 18.00 & 25.00 & 459.00 & 22.9500 & 2.30503 \\
\hline Usefulness of The System to the Problem Solving & 20 & 19.00 & 25.00 & 466.00 & 23.3000 & 1.97617 \\
\hline System Speed for Solving Problems & 20 & 19.00 & 25.00 & 477.00 & 23.8500 & 1.78517 \\
\hline Memory Usage by the System & 20 & 19.00 & 25.00 & 479.00 & 23.9500 & 1.66938 \\
\hline Valid N (listwise) & 20 & & & & & \\
\hline
\end{tabular}

\section{CONCLUSION}

Digital games in particular as a form of entertainment are gaining popularity and hence, numerous educational benefits of computer games cannot be disproved, but there are many issues to resolve before the potential of such a tool is fully harnessed. The greatest impetus is the tussle between commercialism and education. Most commercially-made computer games are based on some inaccurate, badly designed and often violent themes. Learning mathematics as a subject deals with numbers and invariably requires the act of thinking to inductively or deductively connect to meaningful concepts or ideas. Gaming is also an act of hands-on process to make the learner carry out the aspect of doing, thinking out and self-independence in learning process with little or no supervision or support. The system is developed to make the understanding about "factorisation" much simplified to learn as a topic in mathematics. The results of the analysis showed that the system performance is efficient and effective which could promote learning environment to be attractive, interactive and encourage the users to engage in cognitive and constructive process in order to build mental skills.

\section{REFERENCES}

[1] Champion, E. M. "Otherness of place: Game-based interaction and learning in virtual heritage projects", International Journal of Heritage Studies, Vol. 14, pp. 210-228, 2008.

[2] Deleon, N. "Are Video games art?" Available at: http://www.crunchgear.com/2010/04/19/arevideo-games-art. Access on May, 2016.

[3] Funge, J. "Artificial Intelligence for Computer Games: An Introduction”. A K Peters/CRC Press, 2004.

[4] Agbonifo, O. C. and Ogunmoroti, A. O. "A Digital Lego-Based Learning Environment for Fraction Ordering", Nigerian Journal of Technology, Vol. 34, No.4, pp.781-787, 2015.
[5] Connolly, T. M., Stansfield, M., and Hainey, T. “An application of games-based learning within software engineering", British Journal of Educational Technology, Vol. 38, pp. 416-428, 2007.

[6] Gee, J. P. "Reflections on Empirical Evidence on Game and Learning". Ed. S. Tobias \& J. D. Fletcher. Computer Games and Instruction Charlotte, NC: Information Age Publishers pp. 223-233, 2011.

[7] Hein, G. E. "Constructivist learning theory". Available at: http://www.exploratorium.edu/IFI/resources/co nstructivistlearning.html. Accessed on April, 2016.

[8] Merriam and Cafella. "Four Orientation of learning: Categories of Learning Theories". Available at: http://www.lifecircleinc.com/Learrningtheories/orientations.html, Access on May, 2016.

[9] Hay, L. and Robert, T. Flight Simulator Training Effectiveness: A Meta-Analysis. Military Psychology, vol. 4, no. 16, pp. 416-428, 1992

[10] NMI. "New Media Institute. Game-Based Learning: What it is, Why its works, and Where it's going". Available at: http://www.newmedia.org/gamebased-learning-why-it-is-why-it-work-andwhere-its-going.html, Access on June, 2016.

[11] Sun, K. "How to make a fair Scoring System in your Game". Available at: http://www.mrsunstudios.com/2008/09/howto-make-a-fair-scoring-system-in-your-game. Accessed on June, 2016.

[12] Purtadi, S.Y. and Sari, P. "The Implementation of Chempuzzle On Increasing Students' Understanding of Atomic Structure, Elements Periodic System, Chemical Bonding and Basic Laws of Chemistry Concepts, Journal of Education, vol. 1 no. 2 pp. 4-11, 2009. 